\title{
EVALUATION AND MECHANICAL PROPERTIES OF PLASMA ARC WELDED IS2062 STEEL TUBE JOINTS
}

\author{
*Subravel $\mathbf{V}^{1}$ and Prabu $\mathrm{S}^{2}$
}

${ }^{1}$ Department of Mechanical Engineering, Government College of Engineering, Thanjavur, Tamil Nadu- 613402, India ${ }^{2}$ Department of Mechanical Engineering, Government Polytechnic College, Thuvakudi malai, Trichy, Tamil Nadu- 620022, India https://doi.org/10.37255/jme.v15i3pp72-75

\begin{abstract}
In th present work, an attempt has been made to study the effect of plasma arc welding on fusion characteristics of IS 2062 joints. Joints were fabricated using different levels of welding current (140 Amp -160 Amp). The formation of the amount of ferrite in the weld metal controls the microstructural evolution during high-temperature service and higher hardness in the fusion zone, which is due to martensitic formation in the weld zone.
\end{abstract}

Keywords: IS 2062, Plasma Arc welding, Hardness and Microstructure

\section{Introduction}

The plasma welding process was introduced to the welding industry in 1964 as a method of bringing better control to the arc welding process in lower current ranges. Today, plasma retains the original advantages it brought to the industry by providing an advanced level of control and accuracy to produce high-quality welds in miniature or precision applications and to provide long electrode life for high production requirements [1\&2]. Plasma arc welding (PAW) is a process of joining of metals, produced by heating with a constricted arc between an electrode and the workpiece (transfer arc) or the electrode and the constricting nozzle (nontransfer arc). Shielding is obtained from the hot ionised gas issuing from the orifice, which may be supplemented by an auxiliary source of shielding gas.Transferred arc process produces plasma jet of high energy density and may be used for high-speed welding and cutting of Ceramics, steels, Aluminium alloys, Copper alloys, Titanium alloys, Nickel alloys.

Non-transferred arc process produces plasma of relatively low energy density. It is used for welding of various metals and for plasma spraying (coating). Kunio Narita et al. investigated the effect of different welding parameters of plasma arc welding process on the shape of welds and consistency of defects in the flat, vertical and overhead positions of mild steel pipes of thickness $6.4 \mathrm{~mm}$ and outer diameter $406.4 \mathrm{~mm}$ [3].

*Corresponding Author - E-mail: subra.vetri@gmail.com
Astakhin et al. developed plasma arc generators (plasmatron) operating without replacement of the rapidly wearing parts in less than $200 \mathrm{Hrs}$ which are simple in service and provide good protection of the weld zone and stabilisation of the plasma arc [4]. Atsunori Inoue et al. presented the method of measurement for the penetration and the control circuit, which adjusts the pulsed current duration adaptively depending on the results of penetration quality with online measurement. Welding experiment and theoretical analysis indicate that the system can ensure uniform penetration quality under the disturbing condition. Baker et al. reported Tensile, fracture toughness and Fatigue Crack Propagation (FCP) data for a plasma arc weld (PAW) in 4mm thick Ti- 6Al$4 \mathrm{~V}$ alloy sheet. In addition, FCP data is reported for a weld in $9.6 \mathrm{~mm}$ thick Ti-6A1-4V alloy produced by a PAW root weld and TIG filler runs [5]. Ishida et.al investigated the interfacial microstructures and intermetallic compounds produced by plasma arc butt fusion welding of aluminium to mild steel. Experiments were carried out on $5 \mathrm{~mm}$ thick mild steel and aluminium plates. An intermetallic compound alloy layer formed at the interface region between mild steel and aluminium was determined using quantitative metallography, and the mechanism of the intermetallic layer formation and growth was elucidated. Tam et al. studied the process of mechanised plasma arc butt welding of thin gauge mild steel sheets both theoretically and experimentally. The transient temperature distribution has been computed using an analytical model due to Rosenthal. The results were 
compared with those generated by finite element analysis using the commercial package PAFEC.

The available literature are mainly focused on evaluating the mechanical and metallurgical properties of Plasma arc welding. However, very little information available on the effect of pulsed current GTAW parameters such as peak current, base current, pulse frequency and pulse-on- time on mechanical and metallurgical properties of magnesium alloys. Since these pulsed current parameters have a significant influence on fusion zone microstructure and related mechanical properties, understanding the effect of these pulse current parameters is essential. Hence, the present investigation was carried out to study the effect of PAW on cylindrical weld joint of hardness and microstructural characteristics of pulsed current GTA welded AZ31B magnesium alloy.

\section{Experimental work}

In order to achieve the proposed objectives, ASME SA 36 steel and IS 2062 steel was used. Figure 1 shows the base metal before welding. The welding parameters shown in table 1 were defined in order to get a defect-free joint with full penetration. The source used was a Plasma Arc TBA 100. The diameter of the orifice of the nozzle was $1.25 \mathrm{~mm}$, the diameter of the electrode was $2.4 \mathrm{~mm}$, and the torch angle of work was $110^{\circ}$, the electrode angle $50^{\circ}$ and the shielding gas flow.

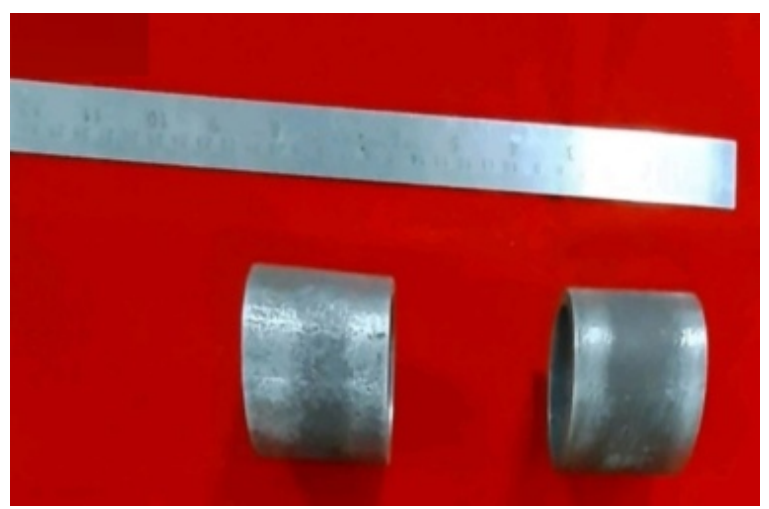

Fig. 1 Specimens to be welded

was $20 \mathrm{l} / \mathrm{min}$. An aluminium plate backing of $5 \mathrm{~mm}$ of thickness was used. The shielding gas was a mixture of Argon-5\% Hydrogen, and the plasma gas employed was Argon. Below Table shows the welding parameters analysed. The standard equation of the HI (AWS, 2001) only takes into account the welding voltage, the welding current and the welding speed. However, in the PAW, the plasma gas flow has an important influence on the actual heat input; therefore, the corrected heat input $\left(\mathrm{HI}^{*}\right)$ is used (Piccini, 2011). Nominal HI was between 110 and $233 \mathrm{~J} / \mathrm{mm}$ and $\mathrm{HI}^{*}$, considering the thermal performance and the effect of the plasma gas flow, ranged between 43 and $115 \mathrm{~J} / \mathrm{mm}$. It can be noted that the $\mathrm{HI}$ and $\mathrm{HI}^{*}$ are very low in comparison with other welding processes. Figure 2 shows the welded specimen.

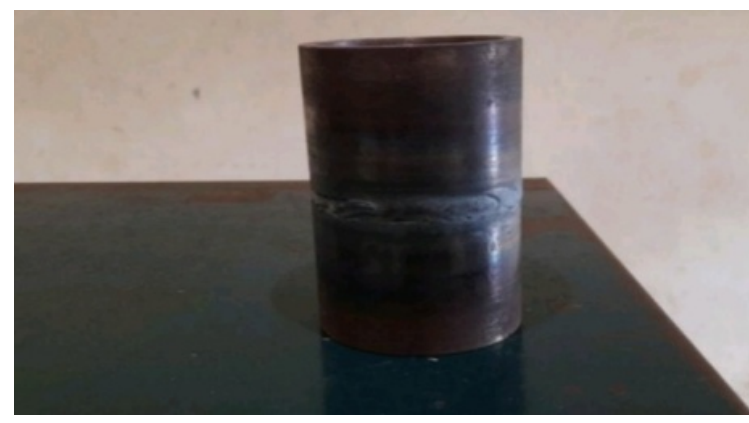

Fig. 2 Welded specimen

From the welded specimens, samples were taken for macro and microstructural characterisation. Metallographic sections were performed on macroscopic examination of all welds through a deep field stereoscopic microscope. The existence of defects in the joints, its geometry and all general aspects of the welds were analysed. Table 2 and 3 present the mechanical properties and chemical composition of the base metal.

Table 1 Process Parameters

\begin{tabular}{|c|c|c|c|c|c|c|}
\hline$\frac{\circ}{\dot{z}}$ & 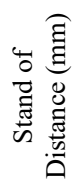 & 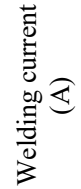 & $\stackrel{ }{\circ} \varepsilon$ & 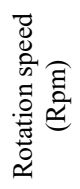 & 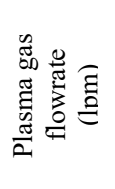 & 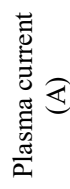 \\
\hline 1 & 2 & 140 & 23.6 & 0.8 & 1.6 & 10 \\
\hline 2 & 2 & 150 & 24.1 & 0.8 & 1.6 & 10 \\
\hline 3 & 2 & 160 & 24.9 & 0.8 & 1.6 & 10 \\
\hline
\end{tabular}

Table 2 Base Metal Mechanical Properties

\begin{tabular}{llll}
\hline & $\begin{array}{c}\text { Yield strength } \\
\text { ReH/(N/mm2) }\end{array}$ & $\begin{array}{c}\text { Tensile strength } \\
\mathrm{Rm} /(\mathrm{N} / \mathrm{mm} 2)\end{array}$ & Elongation A/\% \\
\hline ASME & $(\mathrm{t} \leq 16 \mathrm{~mm})$ & $(3 \mathrm{~mm} \leq \mathrm{t} \leq 16 \mathrm{~mm})$ & $(3 \mathrm{~mm} \leq \mathrm{t} \leq 40 \mathrm{~mm})$ \\
SA 36 & min & & min \\
IS2062 & $250 \mathrm{Mpa}$ & $400-500$ & 20 \\
\hline
\end{tabular}


Table 3 Chemical Composition (wt.\%) of AZ31B Magnesium Alloy

\begin{tabular}{ccccccc}
\hline Grade & $\begin{array}{c}\mathbf{C} \\
(\mathbf{t} \leq \mathbf{1 6 m m})\end{array}$ & $\mathbf{S i}$ & $\mathbf{M n}$ & $\mathbf{P}$ & $\mathbf{S}$ & $\mathbf{N}$ \\
\hline ASMES & 0.026 & 0.040 & - & 0.040 & 0.050 & - \\
A 36 & $\max$ & $\max$ & & $\max$ & $\max$ & \\
& & & & & & \\
IS & $\max 0.23$ & 0.40 & 1.5 & 0.045 & 0.045 & 0.012 \\
2062 & & $\max$ & $\max$ & $\max$ & $\max$ & $\max$ \\
\hline
\end{tabular}

\section{Results and Discussion}

The ability to predict the ferrite content is expressed in terms of Ferrite number (FN), its accuracy has proven to be very useful in assessing the performance and predicting various properties of austenitic SS welds such as strength, toughness, corrosion resistance, etc.34-36 Minimum ferrite content is necessary to avoid hot cracking in SS welds. 37 The presence of delta ferrite in austenitic SS weld metal is beneficial in reducing the tendency of weld solidification cracking and also welds metal- liquation cracking. The amount of ferrite in the weld metal also controls the microstructural evolution during hightemperature service. Moreover, the amount of ferrite controls corrosion and stress corrosion resistance. The weld solidification cracking may increase with increasing ferrite content above approximately FN 30.38. Hence, the quantity of ferrite in the welds must be minimised during welding of austenitic steel joints to avoid material degradation during service. The macrostructure of the joint is shown in figure 3 . The ferrite content present in the microstructural image is shown in figure 4.
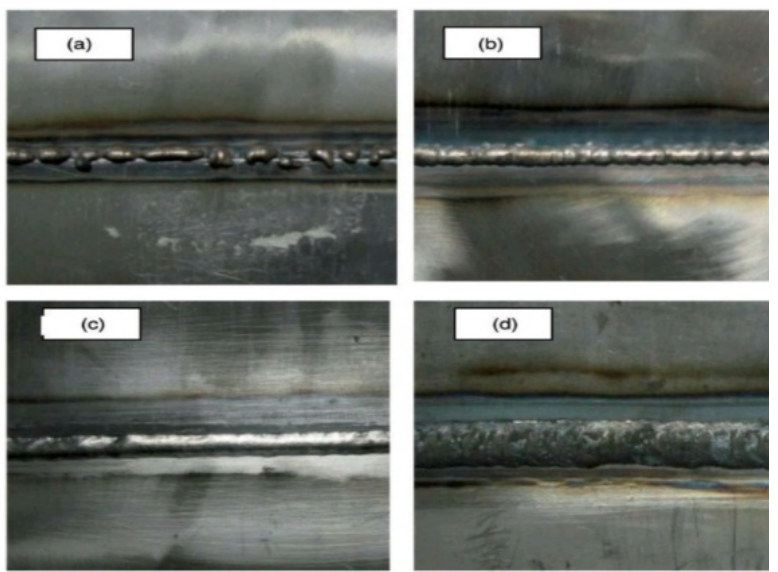

Fig. 3. Micro-image taken on the welded region
From the first set, only two samples were visually accepted. From the second set, three samples were accepted by visual examination. These samples were then tested by liquid penetration examination and radiograph examination according to ASME section $\mathrm{V}$ for subsurface and in surface discontinuities. All the selected samples passed liquid penetration examination and radiograph examination. The selected five samples were then further analysed by measuring weld bead geometry, hardness, microstructure, ferrite measurement and tensile test for weld joint qualification. Table 4 shows the hardness values of the weld.

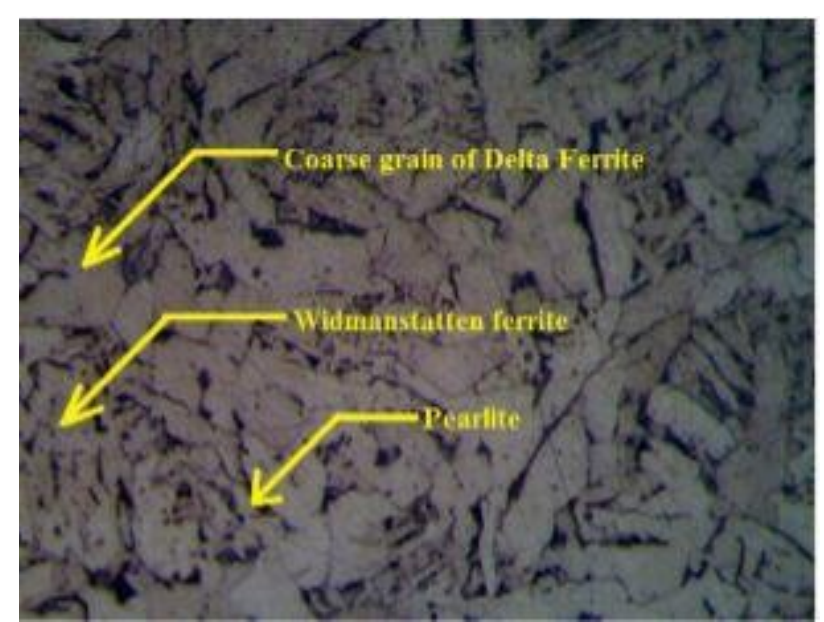

Fig. 4 Ferrite Measurement

Table 4 Hardness Measurement

\begin{tabular}{lc}
\hline $\begin{array}{c}\text { Distance from the } \\
\text { weld center }\end{array}$ & $\begin{array}{c}\text { Hardness } \\
\text { (HV) }\end{array}$ \\
\hline 0 & 186 \\
0.2 & 187 \\
0.4 & 186.2 \\
0.6 & 187.6 \\
0.8 & 189 (High \\
& Hardness) \\
1.0 & 186.3 \\
1.2 & 182 \\
1.4 & 176 \\
1.6 & 170 (Failure Region) \\
1.8 & (HAZ and BM interface) \\
2.0 & 179 \\
\hline
\end{tabular}


Journal of Manufacturing Engineering, September 2020, Vol. 15, Issue. 3, pp 072-075

\section{Conclusions}

From this investigation, the following important conclusions are derived:

i. The investigation revealed that dissimilar metal welding is quite tricky and sound welds can only be obtained by accurate optimisation of process parameters. It was found that weld can be obtained by direct fusion at a higher speed.

ii. The hardness of the weld zone is very high in the weld fusion zone which is due to martensitic formation in the weld zone

iii. An all martensitic structure is found in the weld zone of a directly fused sample.

\section{References}

1. Joseph C, Chen, Ye Li (2009), Taguchi Based Six Sigma Approach to Optimise Plasma Arc Cutting Process: an Industrial Case Study, International Journal of Advanced Manufacturing Technology, 41:760-769.

2. Asiabanpour Bahram (2009), Optimising the automated plasma cutting process by design of experiments, Int. Journal Rapid Manufacturing, 1:19-40.

3. Katsunori Inoue and De-Fu He,(1984), Penetartion-SelfAsaptive Free Frequency Pulsed Plasma Arc Welding Process Controlled with Photocell Sensor, Transactions of JWRI, Vol. 13:7-11.

4. T. S. Baker, (1985), Fatigue crack propagation and fracture toughness of plasma arc welded Ti-6AL-4V alloy, Royal aircraft establishment, Technical report no: 85066.

5. Hatala Michal "Faculty of Manufacturing Technologies of the Technical University of Kosice Sturova The Principle of Plasma Cutting Technology and Six Fold Plasma Cutting”, 5 th International Multidisciplinary Conference. 